\title{
Effect of Dielectric Constant on Asphalt Layers Thickness Based on Ground Penetrating Radar Data Analysis
}

\author{
Audrius Vaitkus (D), Rita Kleizienė (D), Martynas Karbočius \\ Road Research Institute, Vilnius Gediminas Technical University, Vilnius, Lithuania
}

Received 07 March 2020; accepted 15 May 2020

\begin{abstract}
The ground penetrating radar (GPR) in roads is use to investigate the pavement structure layers thickness on network and project level, misaligned dowels and tie bar in concrete pavement, moisture and ground water level, air voids of asphalt layers, and to assure the quality control. Since, pavement layer thickness and materials properties are the key parameters for pavement bearing capacity and residual life determination the effective and reliable GPR analysis procedure is substantial for pavement management system. However, in order to determine asphalt layers thickness the dielectric constant or GPR velocity have to be known. The most common practice to determine the dielectric constant of specific pavement layer is to drill the cores at least every $1 \mathrm{~km}$, as combination of destructive and non-destructive methods. The objective of this study is to investigate the effect of the dielectric constant to asphalt layers thickness determination accuracy. The dielectric constant of asphalt layers and GPR measurements were performed in the $27^{\text {th }}$ pavement sections of the Test Road. The dielectric constant of asphalt layers calculated based on drilled cores data. Analysing the wearing, binder, and base layers separately and in combination. Finally, the errors of determined thicknesses of pavement layers were compared with actual thickness. To determine the dielectric constant influence to the asphalt layer thickness of road sections were investigated by drilling cores and determined the actual thickness. The dielectric constant based on core data and GPR measurements were compared.
\end{abstract}

Keywords: non-destructive testing, ground penetrating radar, GPR, pavement layers thickness, asphalt dielectric constant, GPR velocity.

\section{Introduction}

The pavement management system (PMS) based on functional and structural pavement condition of road network to assess the efficient plan of maintenance activities (Elbagalati et al., 2017). The structural condition and bearing capacity of pavement depends on many factors related to materials type and layer thicknesses of pavement structure. The main inputs for pavement rehabilitation design are based on the layer thickness and deflection data of pavement structure, the bearing capacity and residual life. In addition, the thickness measurements of pavement layers can be also used to control the construction quality of new, rehabilitated or repaired pavement. So, the development of reliable, accurate and fast determination method of layer thickness is on the focus of many researchers (Lahouar \& Al-Qadi, 2008; Lenngren et al., 2000; Willett \& Rister, 2002). The ground-penetrating radar (GPR) is a non-destructive test method capable to collect layer thickness data at short intervals and at traffic speed (Loizos \& Plati, 2007; Liu et al., 2016). GPR is also used to determine the air voids of asphalt layer and bonding of the layers (Sudyka et al., 2018).

GPR performance is based on recording the travel time and reflection amplitude of very high or ultra-high frequency electromagnetic pulses transmitted to the pavement surface (Saarenketo \& Scullion, 2000). There are two basic types of GPR antennas: air-coupled and ground-coupled. Air-coupled (horn) systems operate in the frequency range of 500-2500 MHz. Horn antennas mounted on the vehicle at a height of 0.15 to $0.5 \mathrm{~m}$ above the pavement surface. Ground-coupled systems operate in the frequency range $80-1500 \mathrm{MHz}$ (Saarenketo \& Scullion, 2000). The depth of pulse signal penetration is measured by the operating frequency of antenna. Lower frequency antennas have a higher penetration depth, but higher frequency antennas have a higher resolution. The impulse radar generates short electromagnetic pulse, which transmits into the pavement structure. The electromagnetic pulse penetrates through the pavement layers and reflects a part of signal at surface of material with changed electrical properties. The change of electrical properties can be result of different materials, humidity, density or air voids (Jaselskis et al., 2003; Evans \& Frost, 2011; Wang et al., 2020). However, mostly GPR is used to determine the thickness of the pavement layers, which requires the following conditions (Noureldin et al., 2003):

- the layers of the pavement must be conductive to electromagnetic waves;

${ }^{*}$ Corresponding author. E-mail: martynas.karbocius@vgtu.lt 
- the contact surface of different layers must reflect the electromagnetic signal emitted by the GPR with sufficient energy to record the return signal;

- the physical properties of the different layers of the pavement must be significantly different.

In order to determine the thickness of asphalt layer the dielectric constant $\varepsilon$ or propagation velocity of electromagnetic pulse have to be known or assumed. Typical GPR signal reflection from the asphalt layers is presented in Figure 1. The dielectric constant of asphalt layer calculated according to:

$$
\boldsymbol{\varepsilon}_{1}=\left(\frac{1+A_{1} / A_{m}}{1-A_{1} / A_{m}}\right)^{2},
$$

where: $\varepsilon_{1}$ is the dielectric constant of layer, $A_{1}$ is the amplitude of the reflection from the surface in volts, and $A_{m}$ is the amplitude of the reflection from a large metal plate in volts. The pavement layer assumed to be a homogenous with a constant dielectric property. Based on the travel time $t$ difference of the transmit pulse between two amplitudes the thickness of layers with different dielectric constant materials can be estimated according to:

$$
h_{1}=\frac{c}{\sqrt{\varepsilon_{1}}} \times \frac{\Delta t_{1}}{2},
$$

where: $h_{1}$ is the thickness of asphalt layer, $c$ is the speed of the pulse in air, and $\Delta t_{1}$ is the time delay between the pulse peaks (amplitudes). However, this equation have been proven for asphalt surface layer were no attenuation assumption fits, but may not be correct for asphalt binder and base layers.

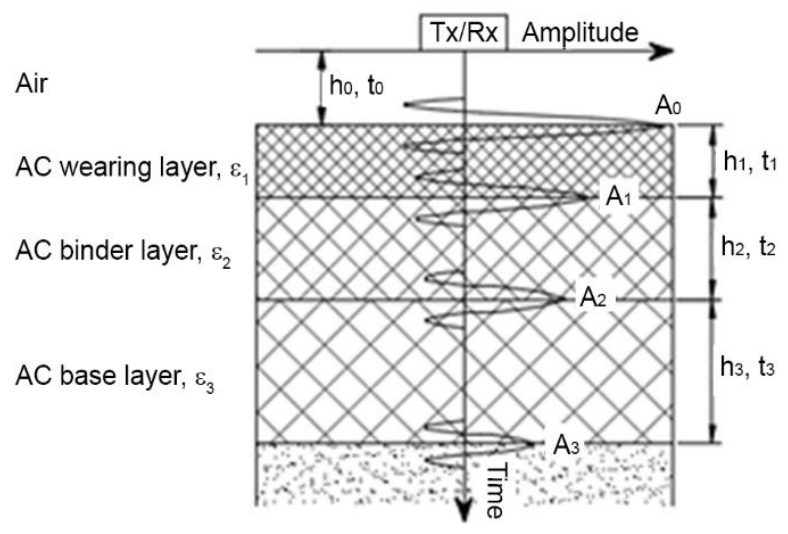

Figure 1. Typical GPR signal reflection for the asphalt layers (Lahouar \& Al-Qadi, 2008)

Since the dielectric constant values have crucial effect to determine the pavement layer thickness, its evaluation procedure have to be reasonable reliable and quick apply. Loizos and Plati (2007) found that the lowest errors of asphalt thickness were in range of 1.4-15.6\%, while the analysis directly from GPR data gives errors in range of $0.9-40 \%$, and the asphalt thickness calculated according to dielectric values estimated in laboratory from cores gives errors of 2.5-16.9\%. AL-Qadi and Lahouar (2005) reported asphalt thickness average absolute error of 3\% when dielectric constants estimated directly from GPR data. However, for this type of analysis, each asphalt layer needs to be evaluated as the dielectric constant of the layer below depends on the layers above. So, the GPR analysis is most accurate to determine the thickness of the asphalt layer, while errors accumulates for each layer below. In addition, the GPR data analysis get more complicated for thin asphalt layer and for disserted pavements in service, when it became hard to distinguish the interfaces between different layers. The most common practice to determine the dielectric constant of specific pavement is to drill cores and combine non-destructive testing of GPR with destructive testing (travel time core thickness analysis). The core drilling every $1 \mathrm{~km}$ is an expensive, time consuming, damaging pavement and disrupting traffic method to specify the dielectric constant need for GPR data analysis.

The objective of this study is to investigate the effect of the dielectric constant to determination accuracy of the thickness of asphalt layers.

\section{Research scope and methods}

The research divided into 4 main stages: GPR and coring data collection, GPR data processing, determination of asphalt layer thickness, and results analysis. The data collection were performed for $16^{\text {th }}$ pavement structures of Test Road of Experimental Pavement Structures (TR EPS) in Pagiriai, which were maintain for 8 years (Čygas et al., 2008). Tested 
pavement structures correspond the same pavement design class with a different material composition of the pavement structure (Vaitkus et al., 2012). A scheme of the study design of effect of dielectric constant on asphalt layers thickness analysis based on ground penetrating radar data is presented in Figure 2.

The test road of Experimental pavement structures measured with the ground penetrating radar Mala ProEx, which consists of $1 \mathrm{GHz}$ ground-coupled antenna and $2.3 \mathrm{GHz}$ air-launched (horn) antenna performing $10 \mathrm{scans} / \mathrm{m}$. Measurements were made on the right and left wheel tracks and between wheel tracks in both lanes. A total of 48 cores were drilled to determine the reference thickness of asphalt layers. The actual asphalt layers thickness from cores are denoted as $\mathrm{h}_{\mathrm{r}}$.

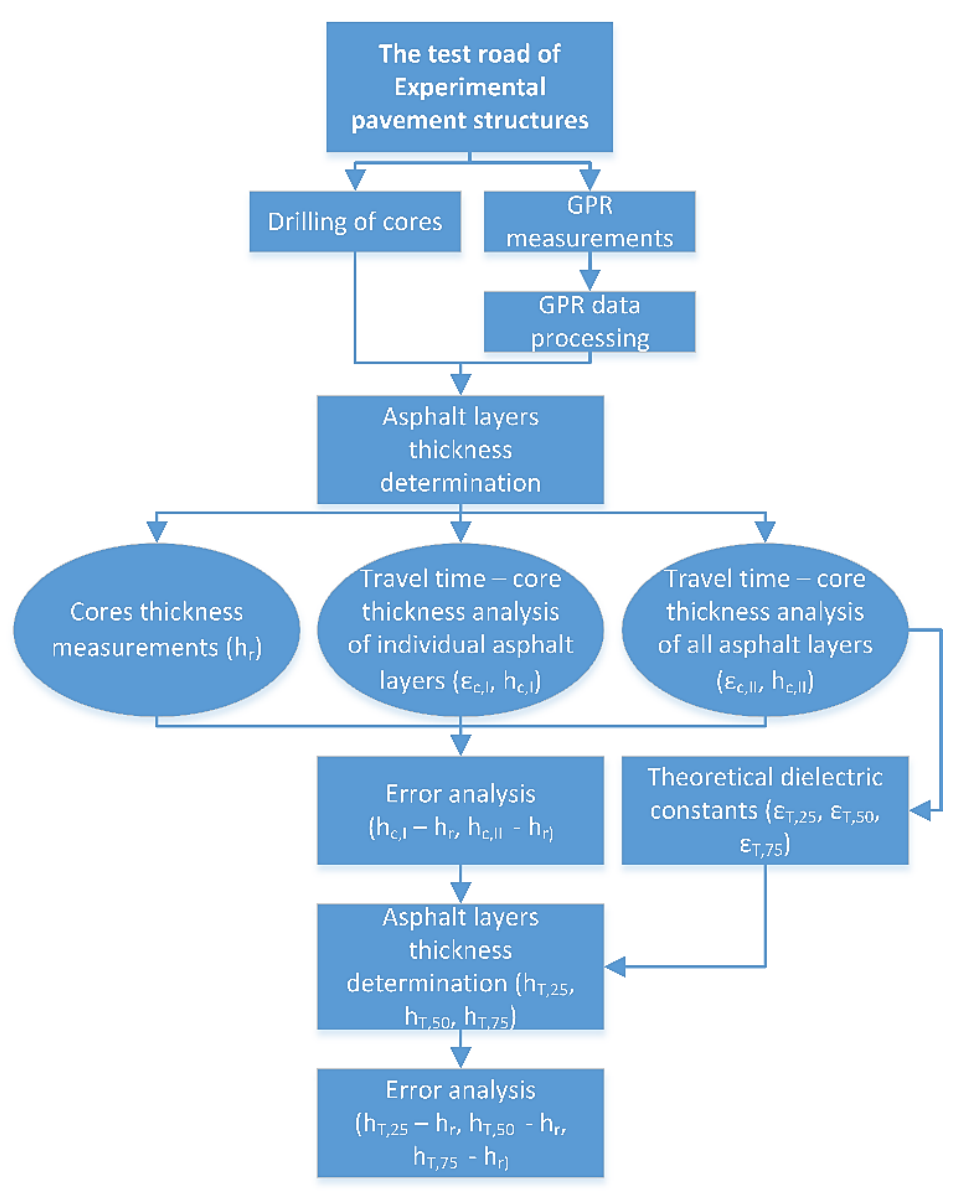

Figure 2. Study design of effect of dielectric constant on asphalt layers thickness analysis based on ground penetrating radar data

During GPR data analysis, the quality of the radargram image is improved by applying certain filters to eliminate noise, signal resonances, and highlight the interfaces of interest, thus reducing the risk of misinterpretation of data (Gregoire et al., 2016). The specialised software REFLEXW 2D was used in this study to process and analyse data by the following filtering sequence:

1. Stationary low-pass (de-wow) filter - removal of lower frequency harmonics by creating within the time range of $0.5 \mathrm{~ns}$ a mean value and subtracting this value from actual data value.

2. Time-zero correction - cutting of the direct waves by removing the first arrivals and the air layer between the antenna and the asphalt surface (first positive peak method).

3. Bandpass frequency filter - removal of low and high frequency components of signals that fall outside the antenna's effective operating frequency range by using of composite low-pass and high-pass filter with a lower cutoff of $1000 \mathrm{MHz}$ and upper cutoff of $4000 \mathrm{MHz}$.

4. Background filter - removal of near-perfect horizontal reflections of the signals (background noise) through the whole time range.

GPR data analysis was performed to determine the dielectric constants and thickness of the individual asphalt layers. Firstly, the interfaces between pavement structure layers were determined. Figure 3 shows an example of GPR data interpretation, along with the asphalt layers interfaces. Following, each asphalt layer was assigned a signal propagation velocity based on the defined interfaces and cores layers thickness. The thickness of each asphalt layer were determined. The sum of each asphalt layer is presented the total thickness of asphalt pavement and denoted as $\mathrm{h}_{\mathrm{c}, \mathrm{I}}$. 
A similar procedure was performed to determine the total thickness of the asphalt pavement, without analysing separate layers. In this case, the interface between the asphalt base layer and the unbound base layer was determined by fixing dielectric constant for all asphalt pavement depth. The total thickness of the asphalt pavement is denoted as $\mathrm{h}_{\mathrm{c}, \mathrm{II}}$.

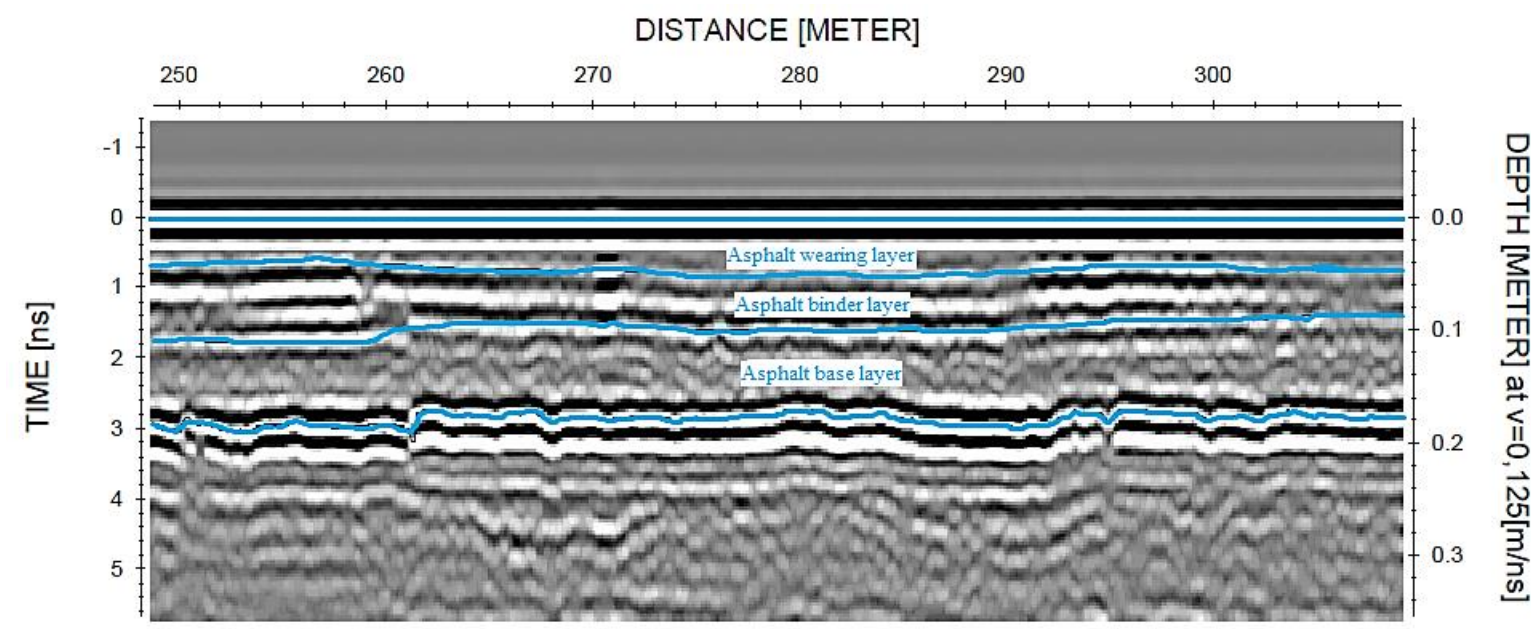

Figure 3. The interpretation of ground-penetrating radar-gram

\section{Results analysis and discussion}

Travel time-core thickness method was used to determine the dielectric constant analysing individual asphalt layers and total asphalt pavement from measures data in the left, middle and right wheel path. The average thickness of four measurement of every individual asphalt layer was determined for 48 cores drilled from TR EPS. The dielectric constant variation of asphalt wearing, binder, and base layers as well as total asphalt pavement layer presented in Figure 4. The analysis showed the wearing and binder layers has the biggest dielectric constant and widest variation. The average dielectric constant of the asphalt wearing layer is 9.5 with a standard deviation (SD) of 2.45. The dielectric constant of the binder layer is $14.2 \%$ lower than wearing layer and is 8.2 with a SD of 2.65. The lowest dielectric constant determined for base layer 4.3 with a SD of 1.3. The density, air voids, and humidity of individual asphalt layers can cause the difference and variation of the dielectric constant. Also, the dielectric properties of asphalt are slightly influenced by temperature changes, as they affect the top layers of asphalt, which are exposed to direct sunlight and other environmental factors (Jaselskis et al., 2003). However, the radar-gram analysis of the asphalt layer interface is complicated, requires experience and precision, since interface selection is done partial manually, which may lead to argumentative result. The average dielectric constant determined according to total thickness of cores is 5.8 and showed the lowest variation of 0.9. This result can be linked to the express pulse amplitude in the interface of asphalt base layer and unbound base layer. So, the dielectric constant variation of layer mostly depends on amplitude magnitude at interface, and to accurately determine the thickness of individual asphalt layers need to consolidate the amplitudes of interface.

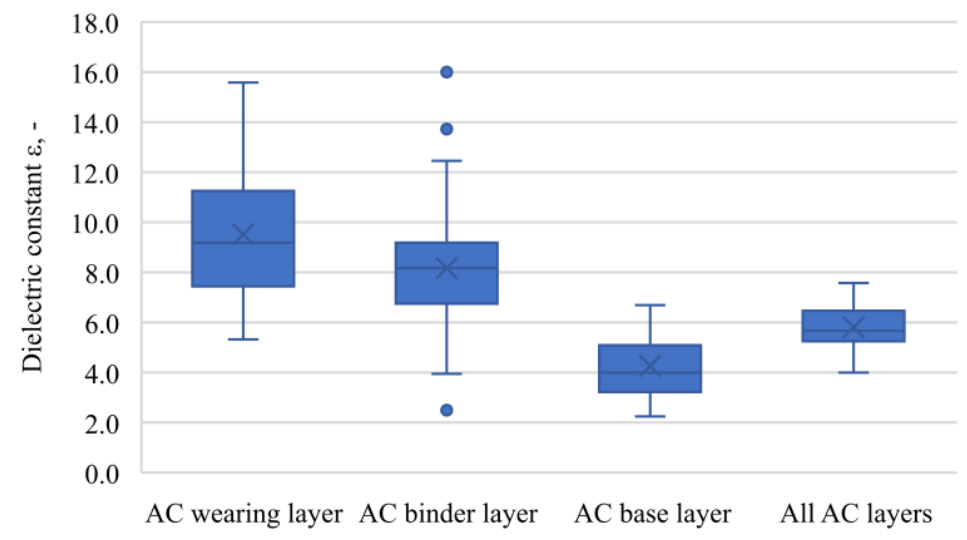

Figure 4. Dielectric constant variation of asphalt wearing, binder, and base layers as well as all asphalt pavement layer 
To investigate the influence of dielectric constant to the total thickness of asphalt pavement the dielectric constant were determined applying different analysis approaches (Table 1):

- the dielectric constant determined using "travel time-core thickness" method for individual asphalt layers thickness for each pavement section;

- the dielectric constant determined using "travel time-core thickness" method for total asphalt pavement thickness for each pavement section;

- the fixed dielectric constant determined analysing left, middle and right wheel path at $25 \%, 50 \%$ (median), and $75 \%$ quartile of dielectric constant for all pavement sections.

Table 1. Methods for determination of thickness of asphalt layers and its denotations

\begin{tabular}{|l|c|c|c|}
\hline \multicolumn{1}{|c|}{ Analysis approach } & $\begin{array}{c}\text { Code of asphalt } \\
\text { thickness analysis }\end{array}$ & Dialectic constant $\varepsilon,-$ & Travel time t, ns \\
\hline Core (reference) of each pavement section & $\mathrm{h}_{\mathrm{r}}$ & - & - \\
\hline $\begin{array}{l}\text { Based on individual asphalt layers } \\
\text { thicknesses (from core) of each pavement } \\
\text { section }\end{array}$ & $\mathrm{h}_{\mathrm{c}, \mathrm{I}}$ & $\begin{array}{l}\text { AC wearing layer 5.3-15.6 } \\
\text { AC binder layer 2.5-16.0 } \\
\text { AC base layer 2.3-6.7 }\end{array}$ & $\begin{array}{l}\text { AC wearing layer 0.6-1.1 } \\
\text { AC binder layer 1.2-1.8 } \\
\text { AC base layer 2.4-3.3 }\end{array}$ \\
\hline $\begin{array}{l}\text { Based on asphalt pavement thicknesses (from } \\
\text { core) of each pavement section }\end{array}$ & $\mathrm{h}_{\mathrm{c}, \mathrm{II}}$ & $4.0-7.6$ & $2.4-3.3$ \\
\hline $\begin{array}{l}\text { Based on theoretical dielectric constant } \\
\text { determined from 25\% quartile of all } \\
\text { pavement sections }\end{array}$ & $\mathrm{h}_{\mathrm{T}, 25}$ & 5.3 & \\
\hline $\begin{array}{l}\text { Based on theoretical dielectric constant } \\
\text { determined from 50\% quartile of all } \\
\text { pavement sections }\end{array}$ & $\mathrm{h}_{\mathrm{T}, 50}$ & 5.7 & - \\
\hline $\begin{array}{l}\text { Based on theoretical dielectric constant } \\
\text { determined from 75\% quartile of all } \\
\text { pavement sections }\end{array}$ & $\mathrm{h}_{\mathrm{T}, 75}$ & 6.2 & - \\
\hline
\end{tabular}

In Figure 5 the total thickness of the asphalt layers determined by different analysis methods of GPR data is compared with reference asphalt pavement thickness. It can be seen that the variation of the results of travel time-core thickness analysis on individual asphalt layers and total thickness of all asphalt layers compared to the reference thickness is quite small as absolute error varies from 0.0 to $1.2 \mathrm{~cm}$ for both analysis methods. Meanwhile, the thickness of the asphalt layers, determined by applying theoretical dielectric constants, varies significantly over a wider range.

The thicknesses of the asphalt layers determined by different analysis methods were also compared with the reference thickness from the cores using a statistical linear regression model. The linear models, based on right wheel track data are presented in Figure 6-10. No significant difference was found between the analysis of the individual asphalt layers and the overall asphalt pavement. The results of the analysis by individual asphalt layers show a closer relationship with the regression line as coefficient of determination is slightly higher. On the other hand, in order to simplify data analysis, it would be appropriate to use a method to determine the overall thickness of the asphalt pavement. Such a method is more practical as it is also applicable to old pavement structures, where a large amount of pavement repairs has been done over a long period of time by laying thin asphalt layers or replacing the upper asphalt layers in local areas. Linear models for thicknesses of asphalt layers determined by theoretical dielectric constants shows significantly lower correlation. However, the highest correlation with the reference thicknesses is demonstrated by the thicknesses of the asphalt layers determined with a $50 \%$ quartile dielectric constant, since the coefficient of determination $\mathrm{R}^{2}=0.586$ is slightly higher compared to $25 \%$ quartile and $75 \%$ quartile.

Asphalt pavement thickness errors depending on different GPR data analysis methods are summarized in Figure 11. As shown in this figure, the variation in thickness error is substantial. Furthermore, the errors generated from analysis based on theoretical asphalt dielectric constants are higher.

Figure 12 shows further statistical information about errors. It is seen that comparing $h_{c, I}$ and $h_{c, I I}$ the error propagation is slightly lower for analysis without evaluating each individual asphalt layer dielectric properties. For $\mathrm{h}_{\mathrm{c}, \mathrm{I}}$, $50 \%$ of errors vary between $0.7 \%$ and $3.6 \%$ with a median of $3.0 \%$. Furthermore, median boxer is noticeably closer to upper edge of box showing a higher concentration of errors between $3.0 \%$ and $3.6 \%$. For $\mathrm{h}_{\mathrm{c}, \mathrm{II}}, 50 \%$ of errors vary between $0.5 \%$ and $3.0 \%$ with a median of $1.7 \%$. Position of median marker demonstrates a slightly higher concentration of errors between $0.5 \%$ and $1.7 \%$. For the analysis according 3 different theoretical dielectric constants the smallest errors were obtained with a 50 percent quartile dielectric constant. For $\mathrm{h}_{\mathrm{T}, 25}$, lower whisker extends to $1.8 \%$ and upper whisker extends to $11.0 \%$. The median of 4.8 is closer to lower edge of the box showing higher concentration of errors between 3.8 and $4.8 \%$. For $\mathrm{h}_{\mathrm{T}, 50}$, errors varies from $0.1 \%$ and $9.8 \%$. The median of 1.8 is closer to lower edge of box showing higher concentration of errors in range of $0.3-1.8$. For $\mathrm{h}_{\mathrm{T}, 75}$, lower whisker extends to $0.8 \%$ while upper 
whisker extends to $9.1 \%$. The median of 3.4 is closer to the lower edge of box showing a higher concentration of errors between $2.0 \%$ and $3.4 \%$.

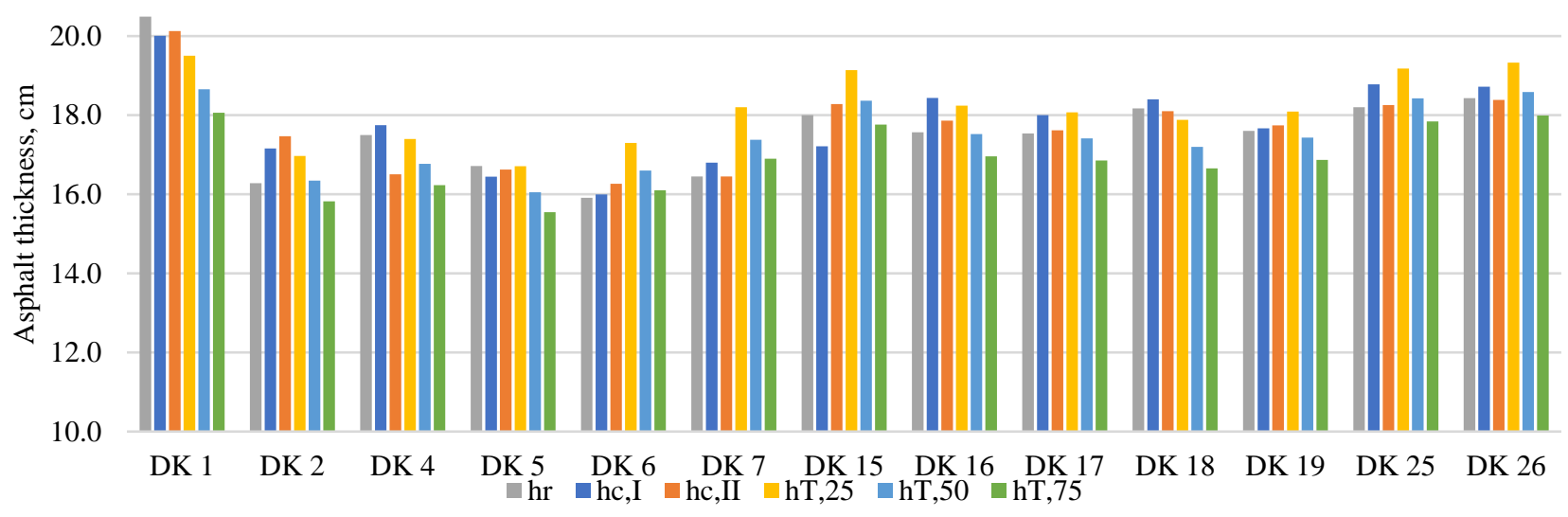

Figure 5. Total asphalt layers thickness based on coring (reference) and GPR estimation

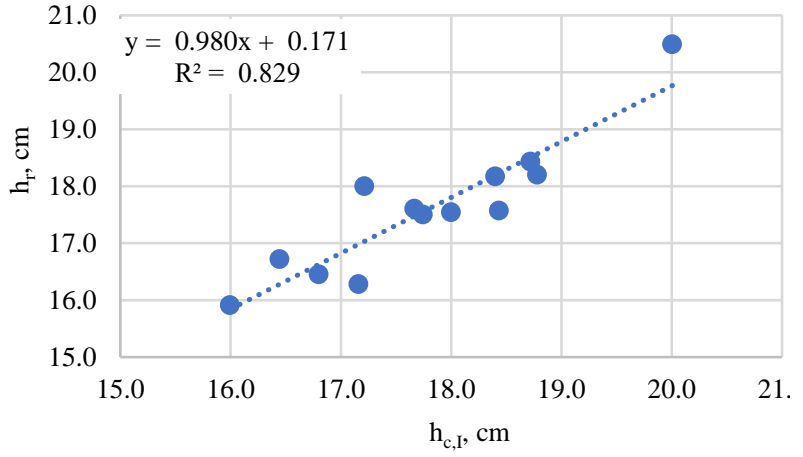

Figure 6. Correlation between $h_{r}$ and $h_{c, I}$

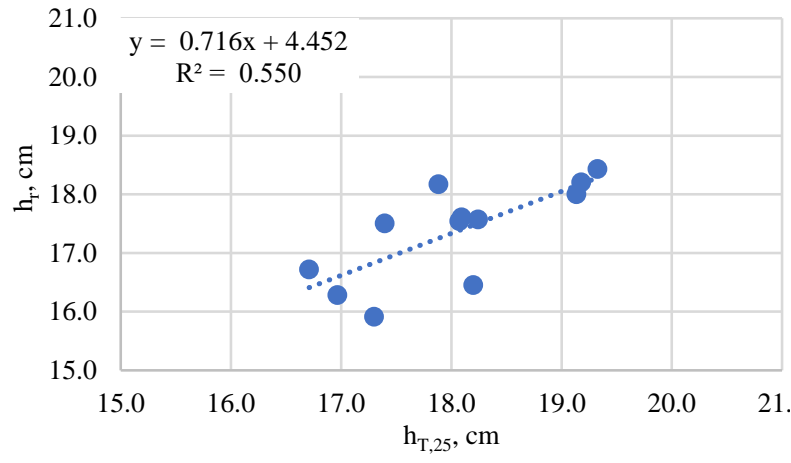

Figure 8. Correlation between $\mathrm{h}_{\mathrm{r}}$ and $\mathrm{h}_{\mathrm{T}, 25}$

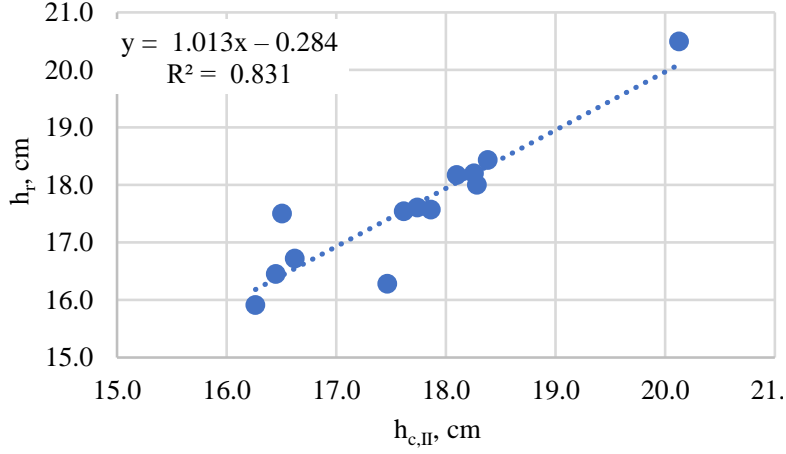

Figure 7. Correlation between $h_{r}$ and $h_{c, I I}$

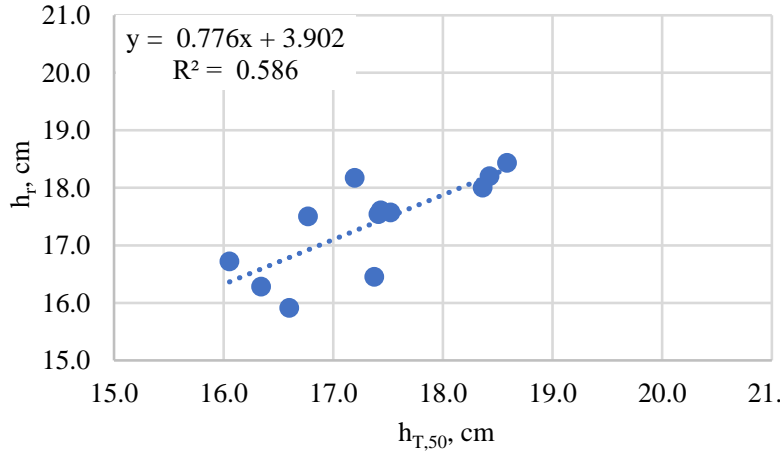

Figure 9. Correlation between $\mathrm{h}_{\mathrm{r}}$ and $\mathrm{h}_{\mathrm{T}, 50}$

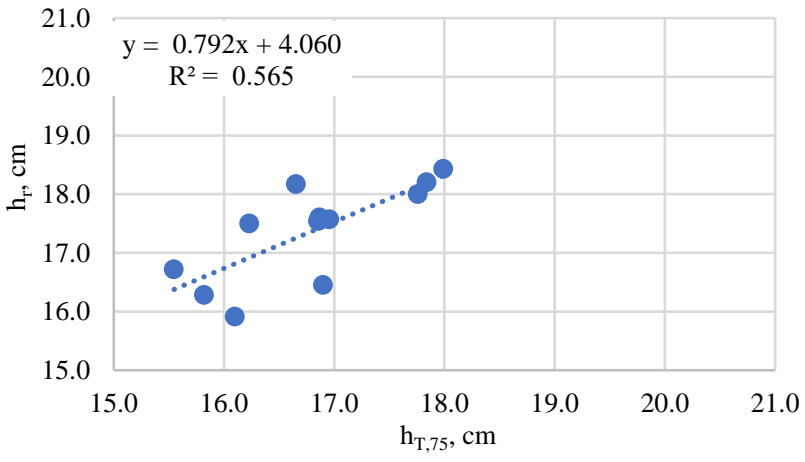

Figure 10. Correlation between $\mathrm{h}_{\mathrm{r}}$ and $\mathrm{h}_{\mathrm{T}, 75}$ 


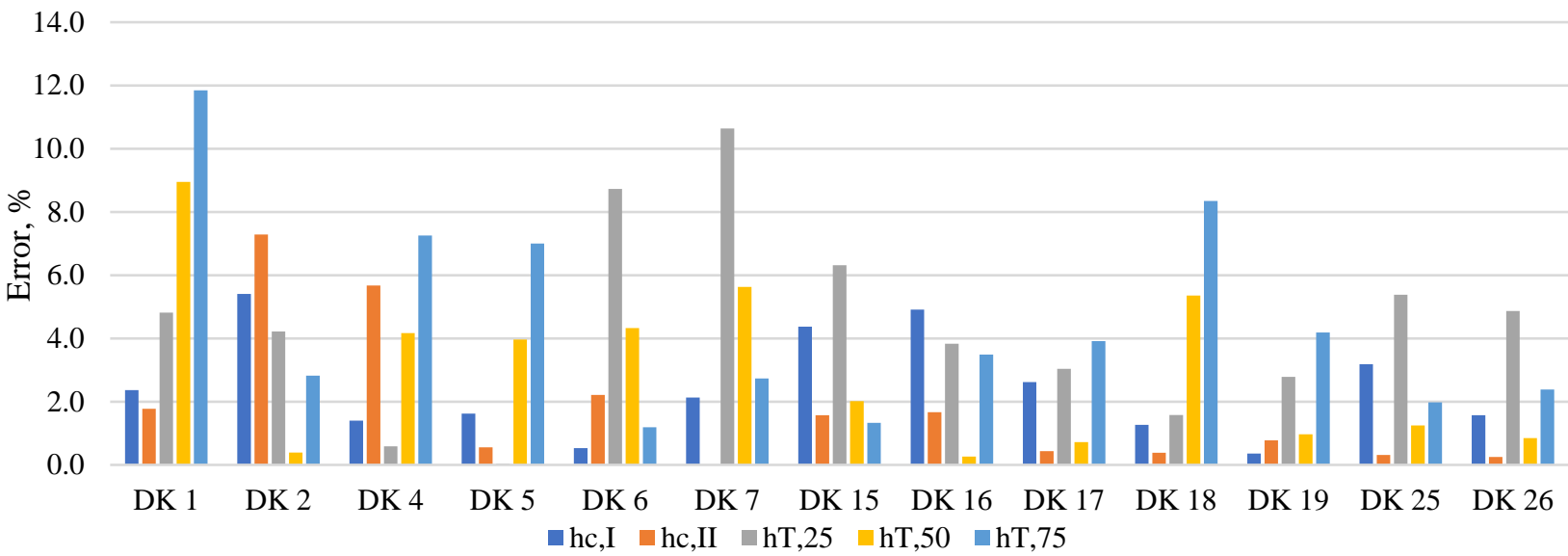

Figure 11. Mean error of asphalt pavement thickness determined applying differently estimated dialectic constant per pavement structures

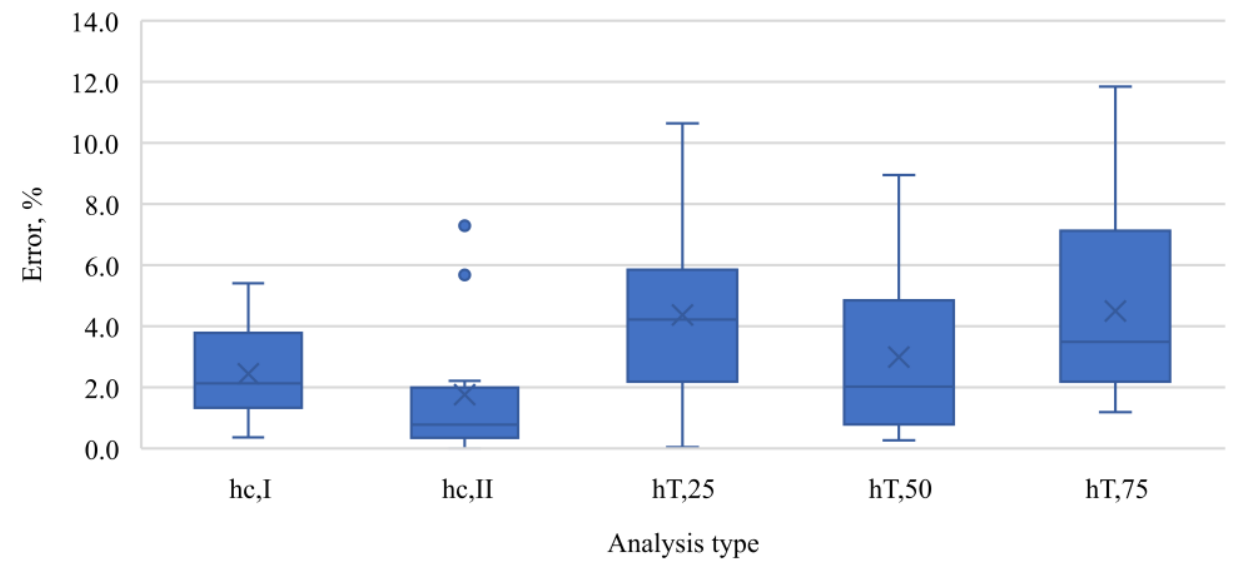

Figure 12. Comparison of asphalt pavement thickness errors depending on different GPR data analysis methods

\section{Conclusions}

Our research explored how the dielectric constatnt analysis method affect the asphalt layer thickness. The dielectric constant was determined from driled cores data and applied in different approches (a) using "travel time-core thickness" method for individual asphalt layers thickness, (b) using "travel time-core thickness" method for total asphalt pavement thickness, and (c) using fixed dielectric constant for total asphalt pavement thickness. The fixed dielectric constant was determined as $25 \%, 50 \%$, and $75 \%$ quartile of all dielectric constantat based on b) approach for left, middle and right wheel path. The main findings and conclusions can be summarised as follow:

1. The average thickness differences between $\mathrm{hr}$ and GPR determined asphalt thickness values, dependent on different method, varied from $0.4 \mathrm{~cm}$, to $1.0 \mathrm{~cm}$. Minimum average difference obtained using "travel timecore thickness" method for individual asphalt layers thicknesses well as for total asphalt pavement thickness. Maximum average differences obtain using fixed 25\% quartile dielectric constant for total asphalt pavement thickness.

2. The accuracy of asphalt pavement thickness determined by dielectric constant for individual asphalt layers and for total asphalt pavement was similar, with a correlation coefficient of 0.83 . However, the median error, determined comparing to core data, was $2.1 \%$ and $0.8 \%$ respectively. This shows that more accurate results can be expected determining one dielectric constant for total asphalt pavement thickness. Furthemore, during investigation of distressed road sections, the establishment of interfaces between individual asphalt layers is often complex and challenging.

3. The assumption of fixed median dielectric constant of 5.7 for all investigated pavement sectors showed reasonable correlation of 0.59 with coring samples. The median error of total asphalt pavement thickness was $2.0 \%$. It confirms the median dielectric constant could be assumed as theoretical value for simplified GPR data analysis in further research.

4. In cases when precise determination of asphalt pavement thickness is needed, there is no option yet to get reliable data without complete elimination of cores drilling. 


\section{Acknowledgements}

The authors thank Dr. Karl-Josef Sandmeier (Sandmeier Geophysical Research), Sr. Engr. Vilhelmas Staskonis (Transport Competency Agency) for meaningful discussions and insights.

\section{Funding}

The authors received no financial support for the research, authorship and publication of this article.

\section{Author contributions}

AV and RK conceived the study and were responsible for the design and development of the data analysis. MK was responsible for data analysis. RK and MK were responsible for data interpretation.

\section{Disclosure statement}

The authors declares that they have no relevant or material financial interests that relate to the research described in this article.

\section{References}

AL-Qadi, I. L., \& Lahouar, S. (2005). Measuring layer thicknesses with GPR - theory to practice. Construction and Building Materials, 19(10), 763-772. https://doi.org/10.1016/j.conbuildmat.2005.06.005

Čygas, D., Laurinavičius, A., Vaitkus, A., Perveneckas, Z., \& Motiejūnas, A. (2008). Research of asphalt pavement structures on lithuanian roads (I). The Baltic Journal of Road and Bridge Engineering, 3(2), 77-83. https://doi.org/10.3846/1822-427X.2008.3.77-83

Elbagalati, O., Elseifi, M. A., Gaspard, K., \& Zhang, Z. (2017). Implementation of the structural condition index into the Louisiana pavement management system based on rolling wheel deflectometer testing. Transportation Research Record, 2641(17), 3947. https://doi.org/10.3141/2641-06

Evans, R. D., \& Frost, M. F. (2011). The effect of moisture on Ground Penetrating Radar (GPR) data from asphalt road pavements. In $5^{\text {th }}$ International Conference Bituminous Mixtures and Pavements (pp. 1-10), Thessaloniki, Greece.

Gregoire, C., Van der Wielen, A., Van Geem, C., \& Drevet, J.-P. (2016). Methodologies for the use of ground-penetrating radar in pavement condition surveys. Brussels.

Jaselskis, E. J., Grigas, J., \& Brilingas, A. (2003). Dielectric properties of asphalt pavement. Journal of Materials in Civil Engineering, 15(5). https://doi.org/10.1061/(ASCE)0899-1561(2003)15:5(427)

Lahouar, S., \& Al-Qadi, I. L. (2008). Automatic detection of multiple pavement layers from GPR Data. NDT\&E International, 41(2), 69-81. https://doi.org/10.1016/j.ndteint.2007.09.001

Lenngren, C. A., Bergström, J., \& Ersson, B. (2000, March). Using ground penetrating radar for assessing highway pavement thickness. Paper presented at the Proceedings of SPIES - The International Society for Optical Engineering. https://doi.org/10.1117/12.390649

Liu, H., Birken, R., \& Wang, M. L. (2016). Automatic pavement layer identification with multichannel ground penetrating radar at traffic speed. Journal of Applied Remote Sensing, 10(4), 046023. https://doi.org/10.1117/1.JRS.10.046023

Loizos, A., \& Plati, C. (2007). Accuracy of pavement thicknesses estimation using different ground penetrating radar analysis approaches. NDT\&E International, 40, 147-57. https://doi.org/10.1016/j.ndteint.2006.09.001

Noureldin, A. S., Zhu, K., Li, S., \& Harris, D. (2003). Network pavement evaluation with falling-weight deflectometer and groundpenetrating radar. Transportation Research Record: Journal of the Transportation Research Board, 1860(1), 90-99. https://doi.org/10.3141/1860-10

Saarenketo, T., \& Scullion, T. (2000). Road evaluation with ground penetrating radar. Journal of Applied Geophysics, 43(2-4), 119-38. https://doi.org/10.1016/S0926-9851(99)00052-X

Sudyka, J., Krysiński, L., Zofka, A., Pszczoła, M., \& Jaskuła, P. (2018). High Frequency impulse ground penetrating radar application in assessment of interlayer connections. MATEC Web of Conferences, 163, 1-8. https://doi.org/10.1051/matecconf/201816302005

Vaitkus, A., Laurinavičius, A., Oginskas, R., Motiejūnas, A., Paliukaite, M., \& Barvidienè, O. (2012). The road of experimental pavement structures: experience of five years operation the road of experimental pavement structures. The Baltic Journal of Road \& Bridge Engineering, 7(3), 220-227.

Wang, S., Al-Qadi, I. L., \& Cao, Q. (2020, May). Factors impacting monitoring asphalt pavement density by ground penetrating radar. NDT and E International, 102296. https://doi.org/10.1016/j.ndteint.2020.102296

Willett, D. A., \& Rister, B. (2002). Ground penetrating radar "Pavement layer thickness evaluation". Kentucky Transportation Center. 